\title{
Rab25 augments cancer cell invasiveness through a $\beta 1$ integrin/EGFR/VEGF-A/Snail signaling axis and expression of fascin
}

\author{
Bo Young Jeong ${ }^{1,7}$, Kyung Hwa Cho ${ }^{1,7}$, Kang Jin Jeong ${ }^{2}$, Yun-Yong Park ${ }^{3}$, Jin Man Kim ${ }^{4}$, Sun Young $\mathrm{Rha}^{5}$, \\ Chang Gyo Park ${ }^{1}$, Gordon B Mills ${ }^{2}$, Jae-Ho Cheong ${ }^{6}$ and Hoi Young Lee ${ }^{1}$
}

The small GTP-binding protein Rab25 is associated with tumor formation and progression. However, recent studies have shown discordant effects of Rab25 on cancer cell progression depending on cell lineage. In the present study, we elucidate the underlying mechanisms by which Rab25 induces cellular invasion. We demonstrate that Rab25 increases $\beta 1$ integrin levels and subsequent activation of EGFR and upregulation of VEGF-A expression, leading to increased Snail expression, epithelial-tomesenchymal transition and cancer cell invasiveness. Strikingly, we identify that Snail mediates Rab25-induced cancer cell invasiveness through fascin expression and that ectopic expression of Rab25 aggravates metastasis of ovarian cancer cells to the lung. We thus demonstrate a novel role of a $\beta 1$ integrin/EGFR/VEGF-A/Snail signaling cascade in Rab25-induced cancer cell aggressiveness through induction of fascin expression, thus providing novel biomarkers and potential therapeutic targets for Rab25-expressing cancer cells.

Experimental \& Molecular Medicine (2018) 50, e435; doi:10.1038/emm.2017.248; published online 26 January 2018

\section{INTRODUCTION}

Rab25 is a member of the Rab11 subfamily and GTP-binding proteins that is exclusively expressed in epithelial cells. ${ }^{1}$ Rab25 mediates recycling of proteins from the endosome to the plasma membrane. ${ }^{2}$ The link between Rab25 and cancer progression was identified through high-density array comparative genomic hybridization (CGH), demonstrating amplification with subsequent overexpression in ovarian and breast cancers. ${ }^{3}$ However, the role of Rab25 in cancer progression appears to be context dependent. Rab25 suppresses breast cancer initiation and progression in triple negative breast cancer, ${ }^{4}$ colorectal adenocarcinoma ${ }^{5}$ and esophageal squamous cell carcinoma. ${ }^{6}$ Conversely, Rab25 expression is closely associated with invasion and metastasis of gastric, ${ }^{7}$ bladder, $^{8}$ ovarian $^{3}$ and luminal breast $^{3,9}$ cancers. Therefore, illumination of the underlying mechanisms by which Rab25 modulates cancer pathophysiology in a context-dependent manner has the potential to reveal novel biomarkers and therapeutic targets for cancer cell progression.

Cancer metastasis is multi-step process that includes epithelial-to-mesenchymal transition (EMT). ${ }^{10}$ Tumor cells detach from neighboring epithelial cells through downregulation of factors in adherens junctions including E-cadherin to begin invasion of the surrounding extracellular matrix. The Snail transcription factor contributes to EMT through downregulation of E-cadherin. Recent studies show that Snail expression is an independent prognostic predictor for progression and patient survival of various cancers, including gastric, ovarian and breast cancers. ${ }^{11-13}$ Furthermore, overexpression of Snail is associated with lymph node metastasis in patients with breast ${ }^{14}$ and gastric cancers. ${ }^{15}$

Fascin is an actin-bundling protein that crosslinks actin filaments into tight, parallel bundles in filopodia and

\footnotetext{
${ }^{1}$ Department of Pharmacology, College of Medicine, Konyang University, Daejeon, Korea; ${ }^{2}$ Department of Systems Biology, The University of Texas MD Anderson Cancer Center, Houston, TX, USA; ${ }^{3}$ Department of Convergence Medicine, Asan Medical Center, University of Ulsan College of Medicine, Seoul, Korea; ${ }^{4}$ Cancer Research Institute, Regional Cancer Center and Infection Signaling Network Research Center, Chungnam National University School of Medicine, Daejeon, Korea; ${ }^{5}$ Divison of Medical Oncology, Yonsei Cancer Center, Yonsei University College of Medicine, Seoul, Korea and ${ }^{6}$ Department of Surgery, Severance Hospital, Yonsei University College of Medicine, Seoul, Korea

${ }^{7}$ These authors contributed equally to this work.

Correspondence: Professor J-H Cheong, Department of Surgery, Severance Hospital, Yonsei University College of Medicine, 50-1 Yonsei-Ro, Seodaemungu, Seoul 03722, Korea.

E-mail: jhcheong@yuhs.ac

or Professor HY Lee, Department of Pharmacology, College of Medicine, Konyang University, 821 Medical Science Building, 158 Gwanjeodong-ro, Seo-gu, Daejeon 35365, Korea.

E-mail: hoi@konyang.ac.kr

Received 15 May 2017; revised 7 July 2017; accepted 23 July 2017
} 
invadopodia ${ }^{16,17}$ that is closely associated with an increased risk of mortality and progression for various cancers including breast, ${ }^{18}$ ovarian $^{19}$ and gastric cancer. ${ }^{19}$ In addition, fascin expression correlates with repression of E-cadherin. ${ }^{20}$ Further, a recent study showed that fascin mediates Slug-induced pancreatic cancer progression, ${ }^{21}$ suggesting that fascin might contribute to EMT and thus cancer progression.

Recently, Rab25 was reported to induce Snail expression and bladder cancer metastasis. ${ }^{22}$ In addition, Cheng et al. ${ }^{4}$ claimed that Rab25 enhances apoptosis and suppresses triple-negative breast cancer aggressiveness through modulation of VEGF-A and VEGFR-1 expression. Further, a recent study suggests a context-dependent role of Rab25 in breast cancer. ${ }^{23}$ However, the detailed underlying mechanisms by which Rab25 aggravates cancer cell EMT and metastasis have not yet been fully characterized in breast cancer and other cancer cells. In the current study, we demonstrate that Rab25 increases the $\beta 1$ integrin level and the consequent activation of EGFR and expression of VEGF-A and Snail in cancer cells. Unexpectedly, we demonstrate that fascin is a downstream target of a Rab25induced $\beta 1$ integrin/EGFR/VEGF-A/Snail signaling axis that regulates cancer cell aggressiveness. Therefore, our results identify mechanisms by which Rab25 modulates cancer cell invasion through coordinated regulation of $\beta 1$ integrin to activation of EGFR and expression of VEGF-A to increase the level of Snail protein and subsequent fascin expression.

\section{MATERIALS AND METHODS}

\section{Reagents}

VEGF $_{165 a a}$ human recombinant protein was purchased from Millipore (Temecula, CA, USA). G418 were acquired from Sigma-Aldrich (St Louis, MO, USA). A VEGF-neutralizing antibody was purchased from R\&D Systems (Minneapolis, MN, USA). Gefitinib was obtained from Selleckchem (Houston, TX, USA). All other reagents were of the purest grade available.

\section{Cell culture}

Breast and ovarian cancer cell lines were purchased from the American Type Culture Collection (Manassas, VA, USA). The gastric cancer cell line MKN-1 was purchased from the Korean Cell Line Bank (Seoul, Korea). MCF-7 cells were cultured in DMEM supplemented with 10\% fetal bovine serum and $1 \%$ penicillin/streptomycin. SKOV-3 and MKN-1 cells were cultured in RPMI-1640 supplemented with $10 \%$ fetal bovine serum and $1 \%$ penicillin/streptomycin. All cells were incubated at $37^{\circ} \mathrm{C}$ under $5 \% \mathrm{CO}_{2}$ in a humidified incubator and routinely tested using a MycoAlert Mycoplasma Detection Kit (LT07218) from Lonza (Allendale, NJ, USA) for negative mycoplasma contamination.

\section{Plasmid and siRNA transfection}

The MCF-7, SKOV-3 and MKN-1 cells were transiently transfected according to the manufacturer's instructions with Lipofectamine 2000 or RNAiMAX (Invitrogen, Carlsbad, CA, USA). Stable overexpression of Rab25 in SKOV-3 cells was established by selecting stable transfectants with G418 $\left(400 \mu \mathrm{g} \mathrm{ml}^{-1}\right)$. The Snail cDNA in pCR3.1 was kindly provided by Dr. J.I. Yook (Yonsei University college of Dentistry, Korea). ${ }^{24}$ The Rab25 cDNA ${ }^{3}$ was subcloned into a pcDNA3 vector, and an empty pcDNA3 vector was used as a negative control. $\beta 1$ integrin constructs were kindly provided by Dr. Y.S Lee (Ewha Woman's University, Seoul). siRNAs of Snail No. 1 (SASI_Hs01_00039785), Snail No. 2 (SASI_Hs01_00039786), VEGFA No. 1 (SASI_Hs01_00201117), VEGF-A No. 2 (SASI_Hs01_00201118), VEGFR-1 No. 1 (SASI_Hs01_00175950), VEGFR-1 No. 2 (SASI_Hs01_00333027), $\beta 1$ integrin No. 1 (SASI_Hs01_00333437), $\beta 1$ integrin No. 2 (SASI_Hs01_00159474) and fascin (SASI_Hs01_00222012) were purchased from SigmaAldrich. Control scrambled siRNA was purchased from Invitrogen. A fascin luciferase reporter vector including the fascin gene $(+2189$ to +2735) subcloned into pGL3 was kindly provided by Dr. Machesky L.M. (CRUK Beatson Institute for Cancer Research, Glasgow, UK). ${ }^{21}$

\section{Quantitative RT-PCR}

Briefly, total cellular RNA was isolated using Trizol (Invitrogen), and $1 \mu \mathrm{g}$ of RNA was reverse transcribed using oligo(dT) and M-MLV reverse transcriptase (Promega, Madison, WI, USA) according to the manufacturer's protocol, as described previously. ${ }^{25}$ Complementary DNA was amplified using an iQ5 Real-Time PCR Detection System (Bio-Rad Laboratories, Hercules, CA, USA) with the following primer sets: Snail, 5'-TTT ACC TTC CAG CAG CCC TA-3' (forward) and 5'GGA CAG AGT CCC AGA TGA GC-3' (reverse); fascin, 5'-ACC TGT CTG CCA ATC AGG AC-3' (forward) and 5'-AGT ACT TGC CCG TGT GGG TA-3' (reverse); VEGF-A, 5'-CAA GGC CAG CAC ATA GGA GA-3' (forward), 5'-ACG CGA GTC TGT GTT TTT GC-3' (reverse); VEGF-B, 5'-AGC ACC AAG TCC GGA TG-3' (forward) and $5^{\prime}$-GTC TGG CTT CAC AGC ACT G-3' (reverse); VEGF-C, 5'-TGC CGA TGC ATG TCT AAA CT- $3^{\prime}$ (forward) and 5'-TGA CAG GTC TCT TCA TCC AGC-3' (reverse); VEGF-D, 5'-GTA TGG ACT CTC GCT CAG CAT- $3^{\prime}$ (forward) and $5^{\prime}$-AGG CTC TCT TCA TTG CAA CAG-3' (reverse); VEGFR-1, 5'-CAG GCC CAG TTT CTG CCA TT-3' (forward) and 5'-TTC CAG CTC AGC GTG GTC GTA-3' (reverse); VEGFR-2, 5' -TGC CTA CCT CAC CTG TTT C-3' (forward) and $5^{\prime}-$ GGC TCT TTC GCT TAC TGT TC-3' (reverse); VEGFR-3, 5'-GGT TCC TCC AGG ATG AAG AC- $3^{\prime}$ (forward) and $5^{\prime}-$ CAA GCA GTA ACG CCA GTG TC-3' (reverse); and glyceraldehyde 3-phosphate dehydrogenase (GAPDH), 5'-CAT CTT CCA GGA GCG AGA-3' (forward) and 5'-CTG CTT CAC CAC CTT CTT GAT-3' (reverse). The GAPDH gene was used as a control for calculation of $\Delta$ Ct. The RT-PCR data were analyzed using the $2^{-(\Delta \Delta \mathrm{Ct})}$ method.

\section{Immunoblotting}

The lysates were resolved by SDS-PAGE. PVDF membranes with proteins were blocked and incubated for $2 \mathrm{~h}$ at room temperature, as described previously. ${ }^{26,27}$ An E-cadherin antibody (610182) was purchased from BD Biosciences (San Jose, CA, USA). Antibodies for Rab25 (4314), Snail (3879), VEGFR-1 (2893) and p-EGFR (4407) were obtained from Cell Signaling Inc. (Danvers, MA, USA). Antibodies for Slug (15391), fascin (21743), Twist (15393), N-cadherin (7939), $\beta 1$ integrin (53711), EGFR (03) and GAPDH (25778) were purchased from Santa Cruz Biotechnology (Santa Cruz, CA, USA). The immunoreactive bands were visualized via ECL (Thermo Fisher Scientific Inc., Rockford, IL, USA) using ImageQuant400 (GE Healthcare, Buckinghamshire, UK).

\section{Immunofluorescence staining}

After cell fixation with cold methanol for $15 \mathrm{~min}$ and permeabilization with $1 \%$ NP-40, immunofluorescence investigation was conducted 
with E-cadherin (610182, 1:100, BD Bioscience), Snail (28199, 1:100, Santa Cruz Biotechnology Inc.) and fascin (21743, 1:100, Santa Cruz Biotechnology Inc.) antibodies overnight, as described previously. ${ }^{28,29}$ The cells were washed with ice-cold phosphate-buffered saline and incubated with Cy2-conjugated goat anti-mouse IgG (111-223-003, green, 1:500; Jackson ImmunoResearch, West Grove, PA, USA) and Cy3-conjugated goat anti-rabbit IgG (111-156-003, red, 1:500; Jackson ImmunoResearch). The nuclei of the cells were counterstained with 4',6'-diamidino-2-phenylindole dihydrochloride (DAPI; Molecular Probes, Carlsbad, CA, USA). The cells were examined by confocal microscopy (LSM710; Carl Zeiss, Jena, Germany).

\section{In vitro invasion assay}

The in vitro invasion assay was performed in triplicate using an invasion assay kit with Matrigel-coated inserts (BD Biosciences), as described previously. ${ }^{30} \mathrm{~A}$ volume of $5 \times 10^{5}$ to $3 \times 10^{6}$ cells per $\mathrm{ml}$ was added to the upper compartment of the invasion chamber with or without pharmacologic inhibitors. To the lower compartment, we added serum-free conditioned medium (DMEM or RPMI, supplemented with $1 \%$ penicillin/streptomycin). After incubation for 16$48 \mathrm{~h}$ at $37^{\circ} \mathrm{C}$, the invaded cells were sequentially fixed, stained with Diff-Quik reagents (Dade Behring Inc., Newark, DE, USA) and quantified by counting the number of cells in five random highpower fields for each replicate $(\times 200)$ under light microscopy.

\section{Luciferase assay}

Cells were co-transfected with $1 \mu \mathrm{g}$ of promoter luciferase reporter constructs and $1 \mu \mathrm{g}$ of $\beta$-galactosidase reporter plasmid using the Lipofectamine 2000 transfection reagent. Luciferase activities and $\beta$ galactosidase activity were assayed using the luciferase and $\beta$-galactosidase enzyme assay system (E1910, Promega). Luciferase activity was normalized to the $\beta$-galactosidase activity in the cell lysate and calculated as an average of three independent experiments.

\section{Chromatin immunoprecipitation analysis}

Chromatin immunoprecipitation (ChIP) analysis was performed using a kit purchased from Upstate Biotechnology (Charlottesville, VA, USA) according to the manufacturer's protocol. The primer sequences of Snail for the fascin promoter are 5'-TCA CAC AGC AAG TGA CCA CA- $3^{\prime}$ (forward), 5'-AAT GTC CCC AAG AGA ACG TG- $3^{\prime}$ (reverse). The PCR product was resolved on a $1.8 \%$ agarose gel and visualized by GelRed Nucleic Acid Gel Staining solution (Biotium, Hayward, CA, USA) and ultraviolet illumination.

\section{Measurement of VEGF concentrations using enzyme-linked immunosorbent assay}

Culture supernatants were collected and used in the determination of VEGF concentrations using a human VEGF-specific enzyme-linked immunosorbent assay (ELISA) kit (DVE00, R\&D Systems) according to the manufacturer's instructions. Mean values were recorded in picograms per milliliter. The results represent triplicate experiments.

\section{In vitro angiogenesis assay}

The angiogenic activity of VEGF produced by the tested cells was analyzed using the In vitro Angiogenesis Assay Kit (Chemicon, Temecula, CA, USA) as described previously. ${ }^{31}$ Human umbilical vein endothelial cells (HUVECs) were cultured in EGM-2 with 20\% FCS, $50 \mathrm{U} \mathrm{ml}^{-1}$ penicillin, $50 \mu \mathrm{g} \mathrm{ml}^{-1}$ streptomycin sulfate, $25 \mu \mathrm{g} \mathrm{ml}^{-1}$ endothelial cell growth supplement, $100 \mu \mathrm{g} \mathrm{ml}^{-1}$ heparin, $2 \mathrm{~mm}$ sodium pyruvate and $1 \mathrm{~mm}$ HEPES at $\mathrm{pH}$ 7.4. HUVECs were serum starved in EGM-2 medium for $8 \mathrm{~h}$ at $37^{\circ} \mathrm{C}$. The supernatant of MCF-7 cells (conditioned medium of cultured cells) was collected and concentrated 10-fold using a $3 \mathrm{~K}$ Ultra centrifugal filter device (Millipore, Billerica, MA, USA). ECMatrix solution was mixed with ECMatrix diluent buffer, distributed to a 96-well plate and allowed to solidify at $37^{\circ} \mathrm{C}$ for $1 \mathrm{~h}$. The serum-starved HUVECs were resuspended with the concentrated supernatant (conditioned medium) and added to ECMatrix-coated 96-well plates, followed by incubation for $12 \mathrm{~h}$. HUVEC capillary tube formation was inspected under an inverted light microscope and measured by counting the branch points in several random fields of view per well (averaged values). The results are taken from the experiment in triplicate of four independent experiments.

\section{Tumor formation in $\mathrm{nu} / \mathrm{nu}$ mice}

For tumorigenesis analysis, stably transfected SKOV-3 cells with Rab25 or control vector $\left(5 \times 10^{6}\right.$ cells in $100 \mu \mathrm{l}$ phosphate-buffered saline) were subcutaneously injected into the flanks of 4 -week-old female nude mice (Nara Biotechnology Co. Ltd, Cheongwon, Korea). Tumor growth was monitored by measuring the tumor diameter with a caliper every 3 days until day 80. The tumor volume was calculated using the following equation: length $\times$ width $^{2} \times 0.52$. To determine the survival time of the mice, the mice were examined for 18 weeks after cell inoculation, at which point the experiment was terminated. For experimental metastasis, the cells with Rab25 or control vector $\left(2 \times 10^{6}\right.$ cells in $200 \mu \mathrm{l}$ phosphate-buffered saline) were injected into mice via the tail vein. After 14 weeks, the mice were killed, and the lungs were collected for analysis of tumor seeding and metastasis. All animal experiments were approved by the Animal Care and Use Committee of Konyang University of College of Medicine.

\section{Immunohistochemical analysis}

Samples from the largest tumors were fixed in formalin for $24 \mathrm{~h}$ at room temperature, embedded in paraffin and sliced for hematoxylin and eosin staining. Immunohistochemistry was performed with primary Rab25 (ab106175, 1:200, Abcam, Cambridge, MA, USA), VEGFR-1 (ab32152, 1:250, Abcam), Snail (ab180714, 1:100, Abcam) and fascin (ab126772, 1:250, Abcam) antibodies, as described previously. ${ }^{25}$ The investigator was blinded during the experiments.

\section{Gene expression data analysis}

Gene expression data from TCGA ovarian cancer cohort were used to analysis for this study (https://tcga-data.nci.nih.gov/tcga/). TCGA breast and ovarian cancer gene expression data were used to calculate the correlation between FSCN1 and SNAI1 based on Pearson's correlation co-efficient value. The correlation value was used in plotting.

\section{Kaplan-Meier (K-M) survival analysis}

Patients in the indicated cohorts were dichotomized by expression of FSCN1 with relatively high expression or relatively low expression and were considered for plotting. The log-rank test was applied to estimate the significance of difference.

\section{Statistical analyses}

Sample sizes were calculated to allow significance. All reported results are taken from three independent experiments performed in triplicate. All experiments were performed by an investigator aware of the experimental hypothesis and reproduced by a blinded investigator. All samples were used in statistical analysis. Data are shown as the 


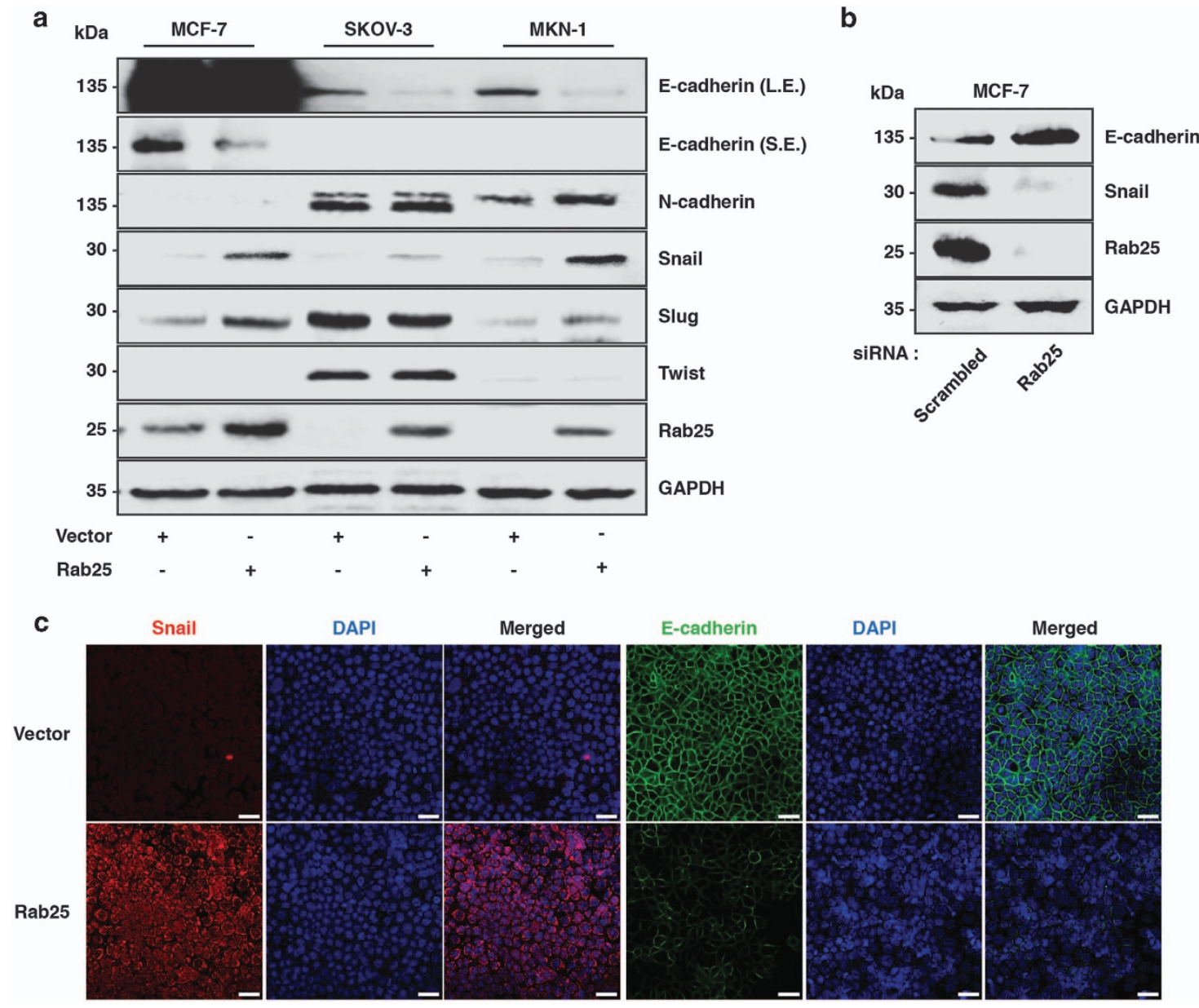

Figure 1 Rab25 modulates cancer cell EMT. (a, b) Cells were transfected with indicated vectors or siRNAs. LE, long-time exposure (60 s), SE, short-time exposure (10 s). Immunoblotting. (c) MCF-7 cells were transfected with indicated vectors, and the expression of E-cadherin and Snail was visualized by immunofluorescence. Original magnification, $\times 200$; scale bar, $20 \mu$ m. Representative results are presented from at least three independent experiments with similar results.

means \pm standard deviation (s.d.). Differences between two groups were assessed with SigmaPlot software (SYSTAT SOFTWARE, San Jose, CA, USA) using the unpaired two-tailed Student's $t$-test. Differences among three or more groups were evaluated by analysis of variance followed by Bonferroni multiple comparison tests.

\section{RESULTS}

\section{Rab25 modulates cancer cell EMT}

Given that EMT is one of the critical steps for cancer cell progression and that Rab25 functions as an enhancer of cancer aggressiveness depending on the type of cancer cells assessed, we first determined how Rab25 changes the expression of various EMT factors. Ectopic expression of Rab25 markedly reduces E-cadherin expression in luminal breast cancer MCF-7, ovarian SKOV-3 and gastric MKN-1 cells (Figure 1a).

In addition, silencing of Rab25 suppressed Snail expression with consequent increased E-cadherin expression in MCF-7 cells (Figure 1b). Further, immunofluorescence analysis confirmed that Rab25 induces Snail expression, whereas E-cadherin expression is reduced in MCF-7 cells (Figure 1c). In addition, transfection of the cells with Snail siRNA recovered Rab25- reduced E-cadherin expression (Supplementary Figure S1). Therefore, these data suggest that Rab25 functions as an inducer of EMT.

\section{Rab25 induces $\beta 1$ integrin expression}

Since Rab25 has been shown to induce $\beta 1$ integrin expression in polarized colonic epithelial cells, ${ }^{32}$ we determined the effects of Rab25 on $\beta 1$ integrin expression in the tested cancer cells. Rab25 significantly induced $\beta 1$ integrin expression in MCF-7 cells (Figure 2a). However, silencing of $\beta 1$ integrin expression dramatically reduced Rab25-induced MCF-7 and SKOV-3 cell invasion (Figure 2b). In addition, ectopic expression of $\beta 1$ integrin induced cancer cell invasion (Figure $2 \mathrm{c}$ ), confirming that $\beta 1$ integrin plays a role in Rab25-induced cancer cell aggressiveness. Further, transfection of the cells with $\beta 1$ integrin siRNA recovered Rab25-reduced E-cadherin expression (Figure 2d, Supplementary Figure S2). Given that Rab25 recycles $\beta 1$ integrin with EGFR, ${ }^{33}$ we subsequently determined whether Rab25 activates EGFR. Indeed, ectopic expression of Rab25 markedly induced EGFR phosphorylation (Figure 2e, Supplementary Figure S2). However, silencing of $\beta 1$ integrin reduced Rab25-induced EGFR phosphorylation, 
a

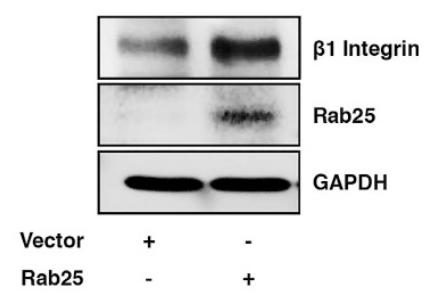

b

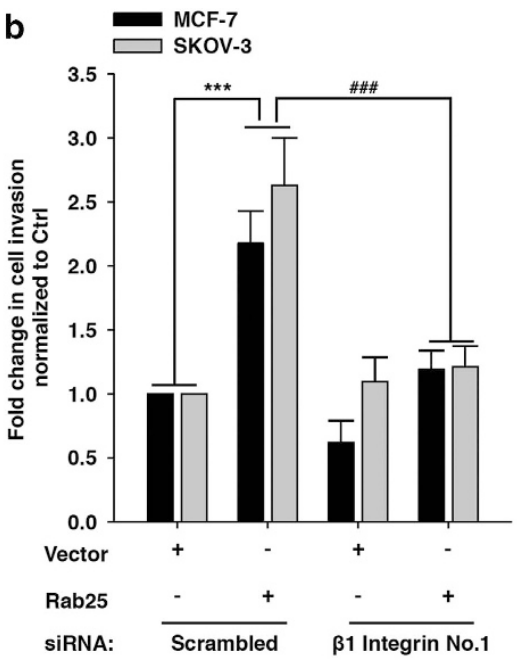

C

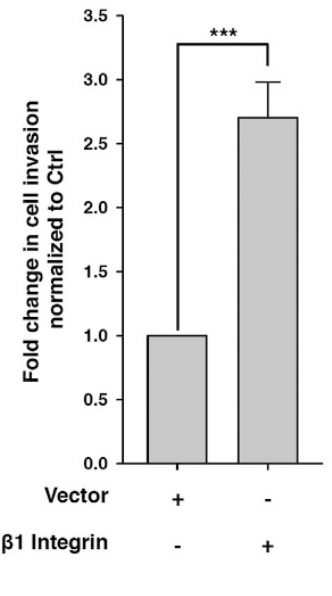

d

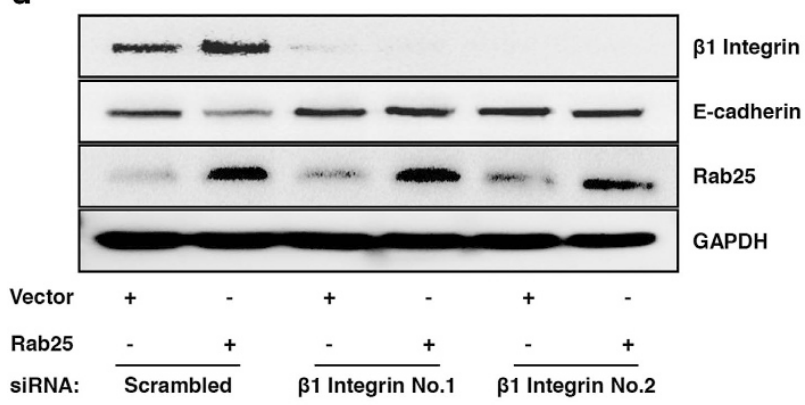

e

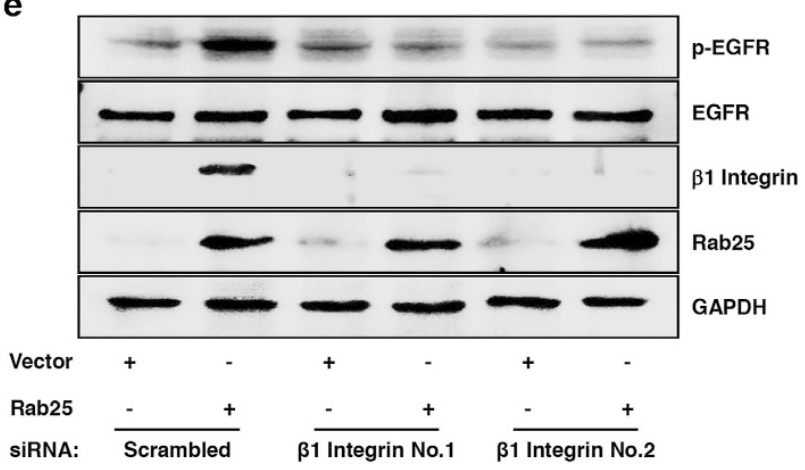

Figure 2 Rab25 induces $\beta 1$ integrin expression. (a) MCF-7 cells were transfected with indicated vectors. Immunoblotting. (b) Cells were co-transfected with indicated vectors and siRNA prior to invasion assay (mean \pm s.d. ${ }^{* * *} P<0.001$ versus control vector with scrambled siRNA, ${ }^{\# \#} P<0.001$ versus Rab25 overexpression with scrambled siRNA). (c) MCF-7 cells were transfected with indicated vector prior to invasion assay (mean \pm s.d. ${ }^{* * * P}<0.001$ versus control vector). (d, e) MCF-7 cells were co-transfected with indicated vectors and siRNAs. Immunoblotting. Representative results are presented from at least three independent experiments with similar results.

suggesting that $\beta 1$ integrin is important for Rab25-induced EGFR activation. Therefore, these data strongly suggest that $\beta 1$ integrin/ EGFR signaling is important for Rab25-induced EMT and cancer cell invasion.

VEGF-A and VEGFR-1 are important for Snail expression Rab25 was previously suggested to suppress VEGF-A secretion and consequent aggressiveness of MDA-MB-231 cells. ${ }^{4}$ Therefore, we explore the role of VEGF and VEGFR in Rab25induced Snail expression and cancer cell EMT. Rab25 induced VEGF-A transcript expression in MCF-7 and SKOV-3 cells (Figure 3a). ELISA analysis also showed that Rab25 induces VEGF-A secretion into the media of MCF-7 and SKOV-3 cells (Figure 3b). We detected little effect of Rab25 on transcript expression of other VEGFs (VEGF-B, VEGF-C and VEGF-D) (Supplementary Figure S3a). In addition, we observed that silencing of VEGF-A expression strongly inhibits Rab25induced Snail expression (Figure 3c,Supplementary Figure S3b) and cancer cell invasion (Figure 3d, Supplementary Figure S3c). Further, Rab25-induced VEGFR-1 (Supplementary Figure S3a), and silencing VEGFR-1 abolished Rab25-induced Snail expression in MCF-7 cells (Figure 3e).
Finally, we observed that conditioned medium of Rab25transfected MCF-7 cells increases HUVEC capillary formation and that conditioned medium of MCF-7 cells transfected with siRNA of VEGF-A or VEGFR-1 abrogates Rab25-induced capillary formation (Figure 3f). Therefore, these data suggest that Rab25 induces Snail expression and angiogenesis through a VEGF-A/VEGFR-1 signaling axis.

Fascin is important for Rab25-induced cancer invasion Given that fascin, an actin-bundling motility-associated protein, is implicated in cancer progression ${ }^{34}$ and that a member of the Snail family of zinc finger transcription factors, Slug, has been reported to induce fascin expression in pancreatic adenocarcinoma cells, ${ }^{21}$ we determined whether fascin contributes to Rab25-induced cancer cell invasion. Interestingly, ectopic expression of Rab25 induced fascin transcripts (Figure 4a), suggesting that Rab25 regulates fascin expression. In addition, we observed that Rab25 induces the promoter activity of fascin (Figure 4b) and that silencing of VEGF-A (Figure 4c) or VEGFR-1 (Figure 4d) significantly reduced Rab25-induced fascin expression. Consistently, stimulation of the cells with VEGF-A markedly upregulated Snail and fascin 

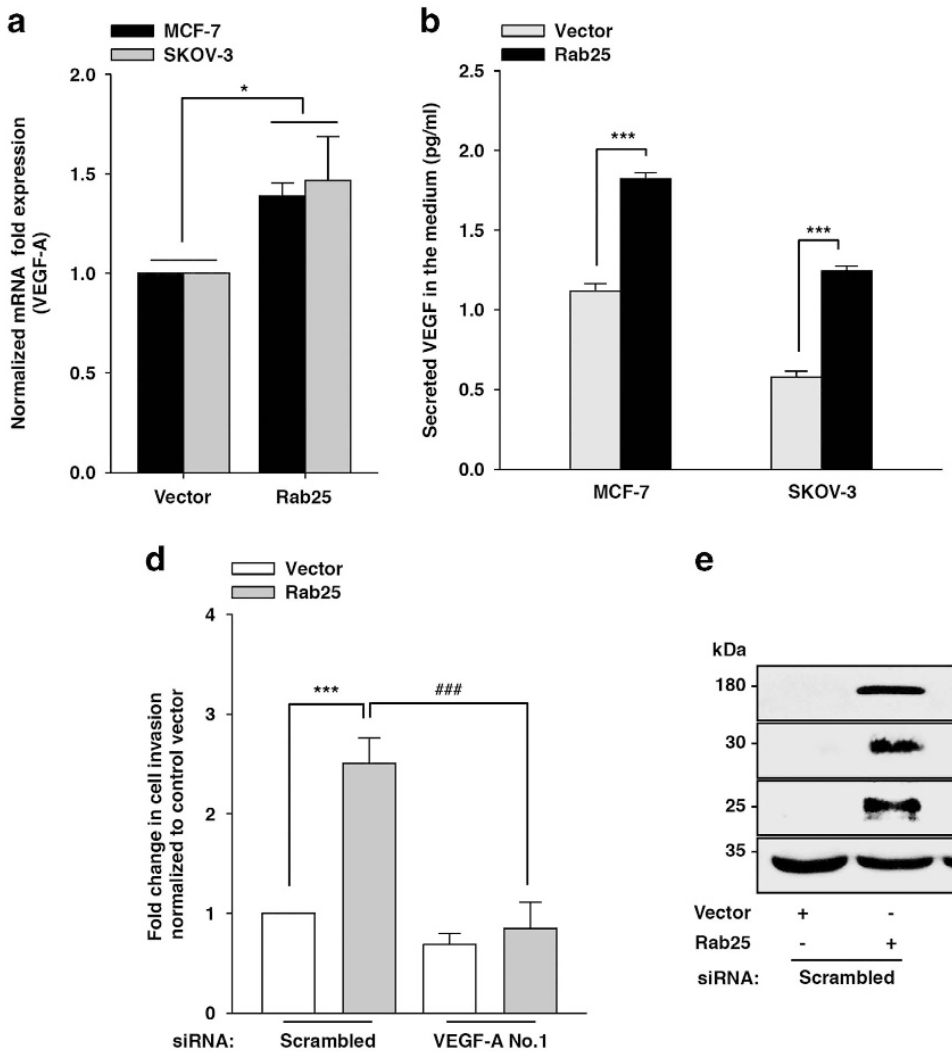

f

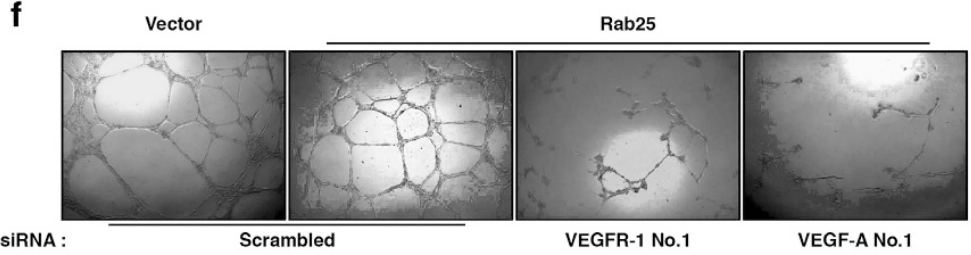

e
C

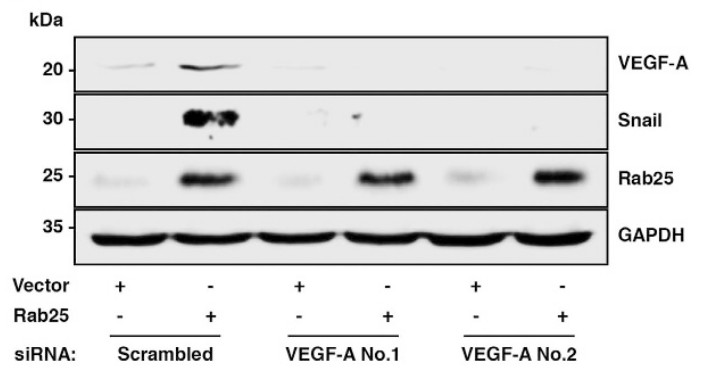

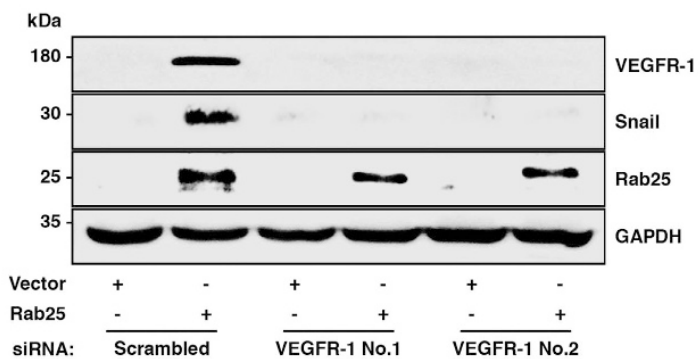

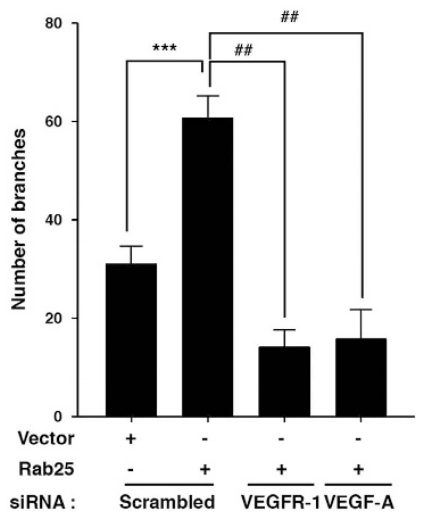

Figure 3 VEGF-A and VEGFR-1 are important for Snail expression. (a) Cells were transfected with indicated vectors. Quantitative RT-PCR (mean \pm s.d. ${ }^{*} P<0.05$ versus control vector). (b) Cells were transfected with indicated vectors. ELISA assay (mean \pm s.d. ${ }^{* * *} P<0.001$ versus control vector). (c) MCF-7 cells were co-transfected with indicated vectors and siRNAs. Immunoblotting. (d) MCF-7 cells were cotransfected with indicated vectors and siRNAs. Invasion assay (mean \pm s.d. $* * * P<0.001$ versus control vector with scrambled siRNA, ${ }^{\# \# \# P}<0.001$ versus Rab25 overexpression with scrambled siRNA). (e) MCF-7 cells were co-transfected with indicated vectors and siRNAs. Immunoblotting. (f) MCF-7 cells were co-transfected with indicated vectors and siRNAs for $48 \mathrm{~h}$. HUVEC capillary tube formation assay (mean \pm s.d. ${ }^{* * *} P<0.001$ versus control vector with scrambled siRNA, ${ }^{\# \#} P<0.01$ versus Rab25 overexpression with scrambled siRNA). Representative results are presented from at least three independent experiments with similar results.

expression concomitant to reduced E-cadherin expression (Figure 4e,Supplementary Figure S4a). However, transfection of the cells with Slug siRNA did not inhibit VEGF-induced fascin expression (Figure 4f). More importantly, silencing of fascin expression significantly attenuated Rab25- and VEGFinduced cancer cell invasion (Figure $4 \mathrm{~g}$ and h,Supplementary Figure S4b). Finally, blocking of VEGF by a VEGF neutralizing antibody (VEGF ab) completely inhibited Rab25-induced Snail and fascin expression (Figure 4i). Therefore, these data suggest that Rab25 induces fascin expression through a VEGF-A/
VEGFR-1/Snail signaling axis and that fascin is important for Rab25-induced cancer aggressiveness.

\section{Snail mediates Rab25-induced fascin expression}

We next explored whether Snail contributes to Rab25-induced fascin expression. Ectopic expression of Rab25 induced fascin mRNA expression (Figure 5a). However, silencing of Snail expression significantly attenuated Rab25-induced fascin transcript expression. Consistently, transfection of cells with Snail siRNA strongly inhibited Rab25-induced fascin protein 
a

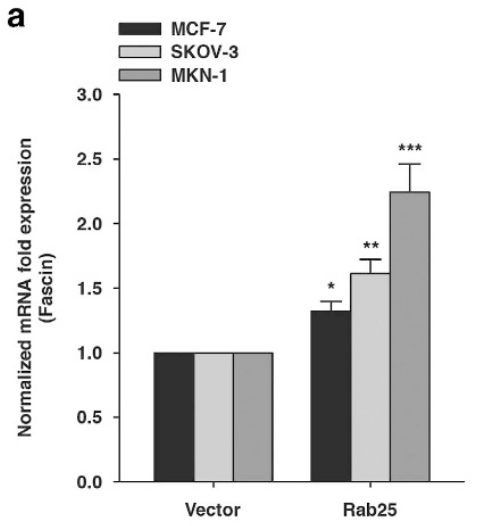

b

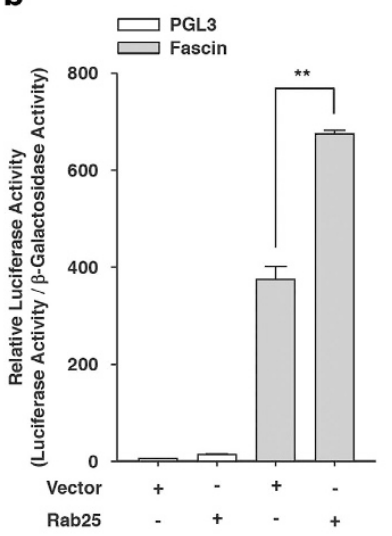

C

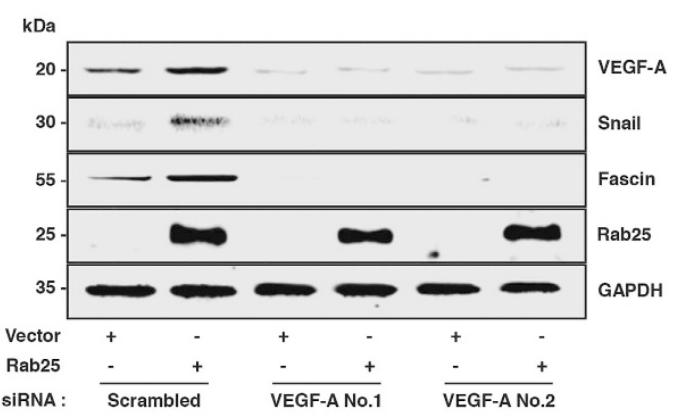

$\mathbf{d}_{\mathrm{kDa}}$

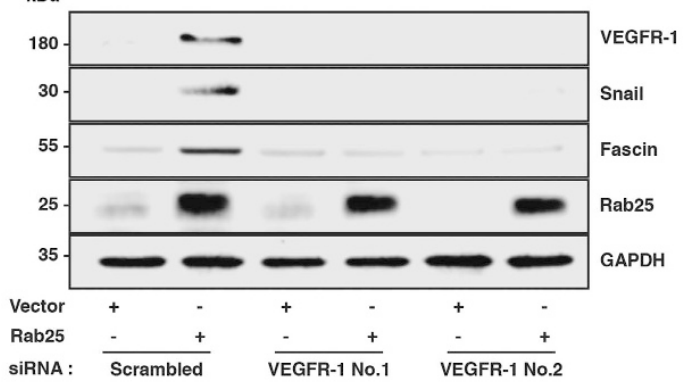

e

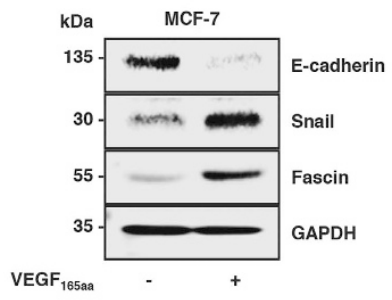

f

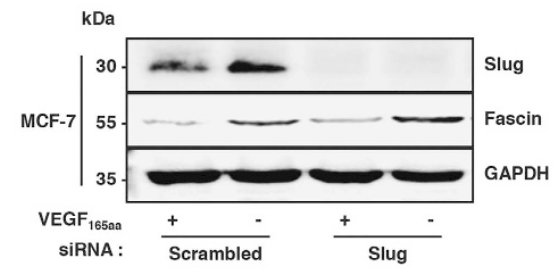

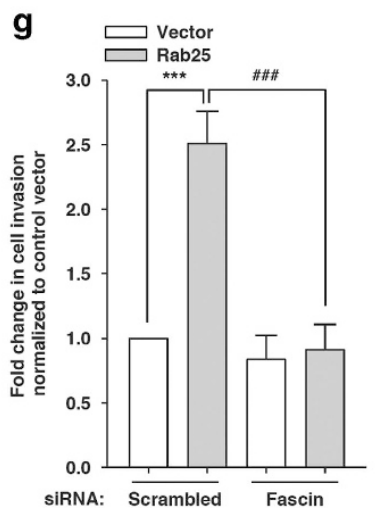

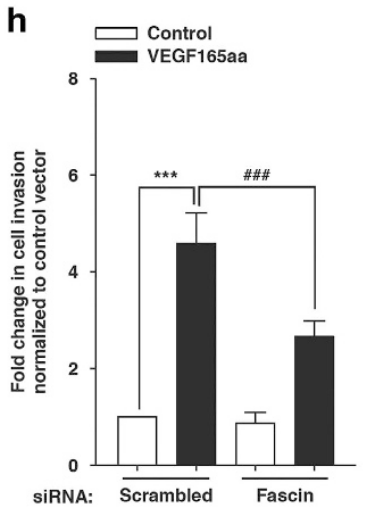

i

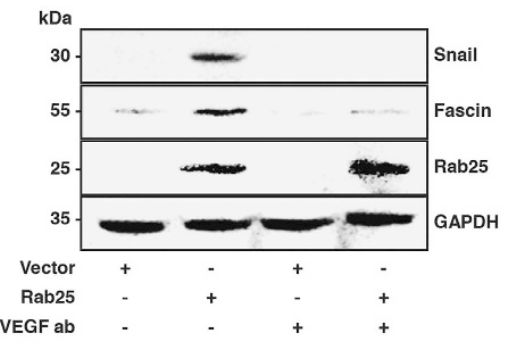

Figure 4 Fascin is important for Rab25-induced cancer invasion. (a) Cells were transfected with indicated vectors. Quantitative RT-PCR (mean \pm s.d. ${ }^{*} P<0.05,{ }^{* *} P<0.01$ and ${ }^{* *} P<0.001$ versus control vector). (b) SKOV-3 cells were co-transfected with indicated vectors. Luciferase activity (mean \pm s.d. ${ }^{* *} P<0.01$ versus Rab25 with Fascin promoter overexpression). (c, d) MCF-7 cells were co-transfected with indicated vectors and siRNAs. Immunoblotting. (e) MCF-7 cells were stimulated with VEGF 165 aa $\left(50 \mathrm{ng} \mathrm{ml}^{-1}\right)$ for $1 \mathrm{~h}$. Immunoblotting. (f) MCF-7 cells were transfected with indicated siRNAs, serum starved and stimulated with VEGF $165 a$ a $\left(50 \mathrm{ng} \mathrm{ml}^{-1}\right)$ for $1 \mathrm{~h}$. Immunoblotting. (g) MCF-7 cells were co-transfected indicated vectors and siRNAs. Invasion assay (mean \pm s.d. ${ }^{* * *} P<0.001$ versus control vector with scrambled siRNA, ${ }^{\# \# P} P<0.001$ versus Rab25 overexpression with scrambled siRNA). (h) SKOV-3 cells were transfected with indicated siRNAs, serum-starved and treated with $\operatorname{VEGF}_{165 a a}\left(50 \mathrm{ng} \mathrm{ml}^{-1}\right.$ ). Invasion assay (mean $\pm \mathrm{SD}{ }^{* * *} P<0.001$ versus scrambled siRNA, \#\# $P<0.001$ versus scrambled siRNA with VEGF $_{165 a a}$ ) (i) MCF-7 cells transfected with indicated vectors were treated with VEGF neutralizing antibody (VEGF $\mathrm{ab}, 5 \mu \mathrm{g} \mathrm{ml}-1,24 \mathrm{~h}$ ). Immunoblotting. Representative results are presented from at least three independent experiments with similar results.

expression (Figure 5b), suggesting that Snail mediates Rab25induced fascin expression. In addition, we observed that ectopic expression of Snail was sufficient to induce fascin expression (Supplementary Figure S5). We subsequently determined whether VEGF-A and VEGFR-1 contribute to Rab25-induced fascin expression. Immunofluorescence data show that silencing of Snail, VEGF-A and VEGFR-1 expression markedly reduced Rab25-induced fascin expression (Figure 5c), suggesting that the
VEGF-A/VEGFR-1/Snail signaling axis is critical for Rab25induced fascin expression. Further, VEGF upregulated fascin expression (Figure 5d) and binding of Snail to the fascin promoter (Figure 5e).

Gene expression data in the $\mathrm{K}-\mathrm{M}$ plot shows that FSCN1 (for fascin) expression correlates with breast, ovarian and gastric cancer patient outcomes (Figure 5f). Further, we used the TCGA data cohort to determine the clinical 


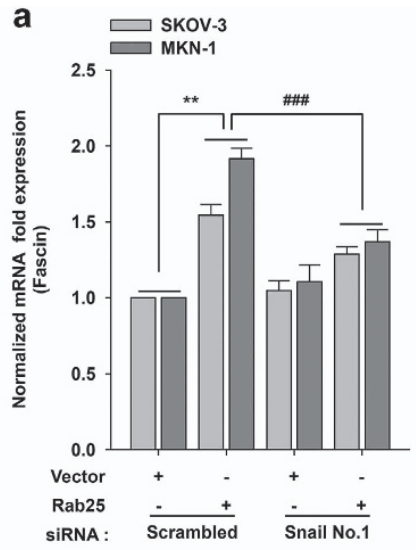

C

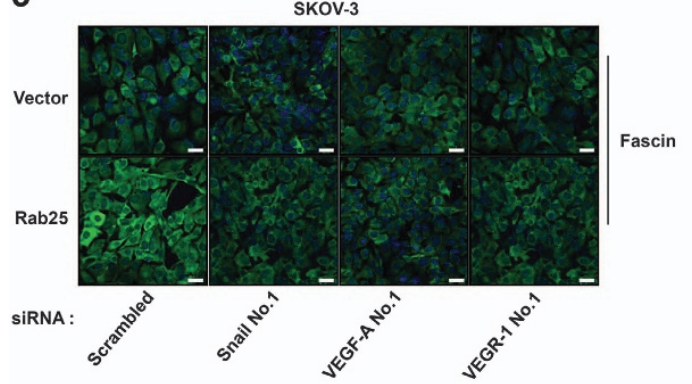

f

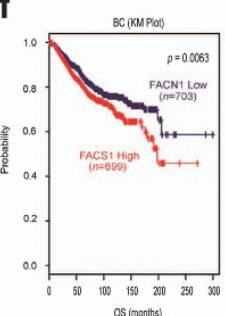

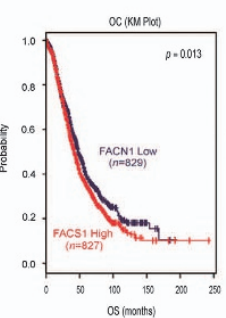

b
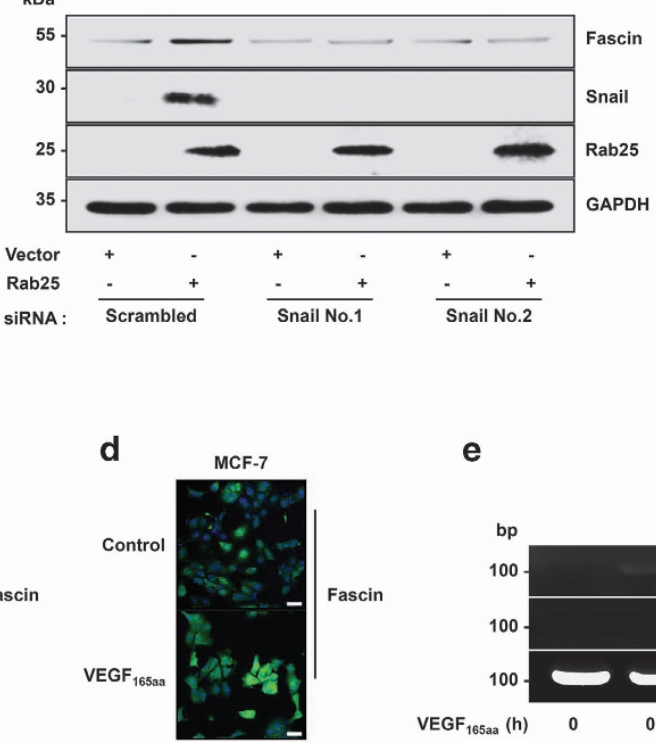

e

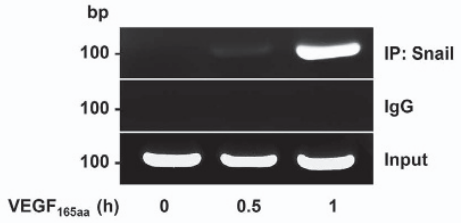

Figure 5 Snail mediates Rab25-induced fascin expression. (a) Cells were co-transfected with indicated vectors and siRNAs. Quantitative RT-PCR for fascin mRNA expression (mean \pm s.d. ${ }^{* *} P<0.01$ versus control vector with scrambled siRNA, \#\#\# $P<0.001$ versus Rab25 overexpression with scrambled siRNA). (b) MCF-7 cells were co-transfected with indicated vectors and siRNAs. Immunoblotting. (c, d) Cells were co-transfected with indicated vectors and siRNAs (c), or stimulated with VEGF $165 a \mathrm{a}$ (d). Immunofluorescence with an anti-fascin antibody. Original magnification, $\times 200$; scale bar, $20 \mu \mathrm{m}$. (e) SKOV-3 cells were stimulated with VEGF 165 aa. ChIP analysis. (f) Correlation between FSCN1 gene expression and overall survival in breast (BC), ovarian (OC) and gastric (GC) cancer patients, $P=0.01$. The K-M plot was drawn in 'kmplot.com'. (g) Correlation between FSCN1 and SANI1 gene expression in breast, ovarian and gastric cancer patients.

implication of SNAI1 (for Snail) and FSCN1 and observed that SNAI1 expression is significantly correlated with FSCN1 expression (Figure 5g). Therefore, these results suggest that Snail mediates Rab25-induced fascin expression and cancer invasion.

\section{Rab25 increases tumorigenesis and metastasis}

As EMT is a critical component of the metastatic cascade, we determined whether Rab25 could contribute to in vivo tumorigenesis and metastasis by injecting SKOV-3 cells stably transfected with Rab25 into nude mice. We observed that mice injected with Rab25-transfected cells had much larger tumors than those with vector-transfected cells (Figure 6a). Analysis of the tumor growth curves indicates that the difference was significant at 8 weeks after cell injection. We subsequently evaluated the lungs for tumor seeding. We observed much larger and higher numbers of metastatic colonies in the lungs of the mice implanted with SKOV-3 cells with ectopic expression of Rab25 compared with the control vector (Figure $6 \mathrm{~b}$ and $\mathrm{c}$ ). Further, RT-PCR analysis showed stronger VEGF-A, VEGFR-1, Snail and fascin mRNA expression in the lung tissues from mice bearing SKOV-3 cells with ectopic expression of Rab25 compared with cells expressing control vector (Figure 6d). Consistent with these findings, immunohistochemical analysis showed much higher VEGFR-1, Snail and fascin expression in lung tissues from mice bearing SKOV-3 cells with ectopic expression of Rab25 compared with mice bearing SKOV-3 cells transfected with control vector (Figure 6e). Therefore, these results strongly suggest that Rab25 increases cancer cell metastasis through a VEGF-A/VEGFR-1/ Snail/fascin signaling axis. 

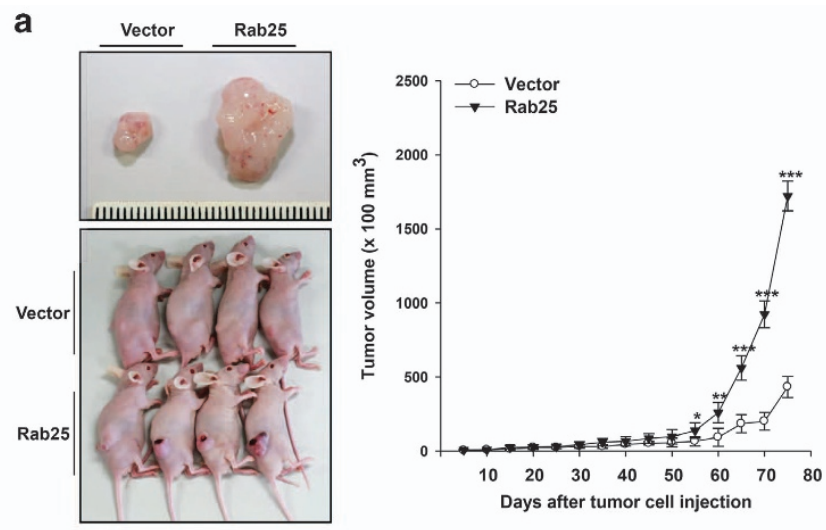

b

C
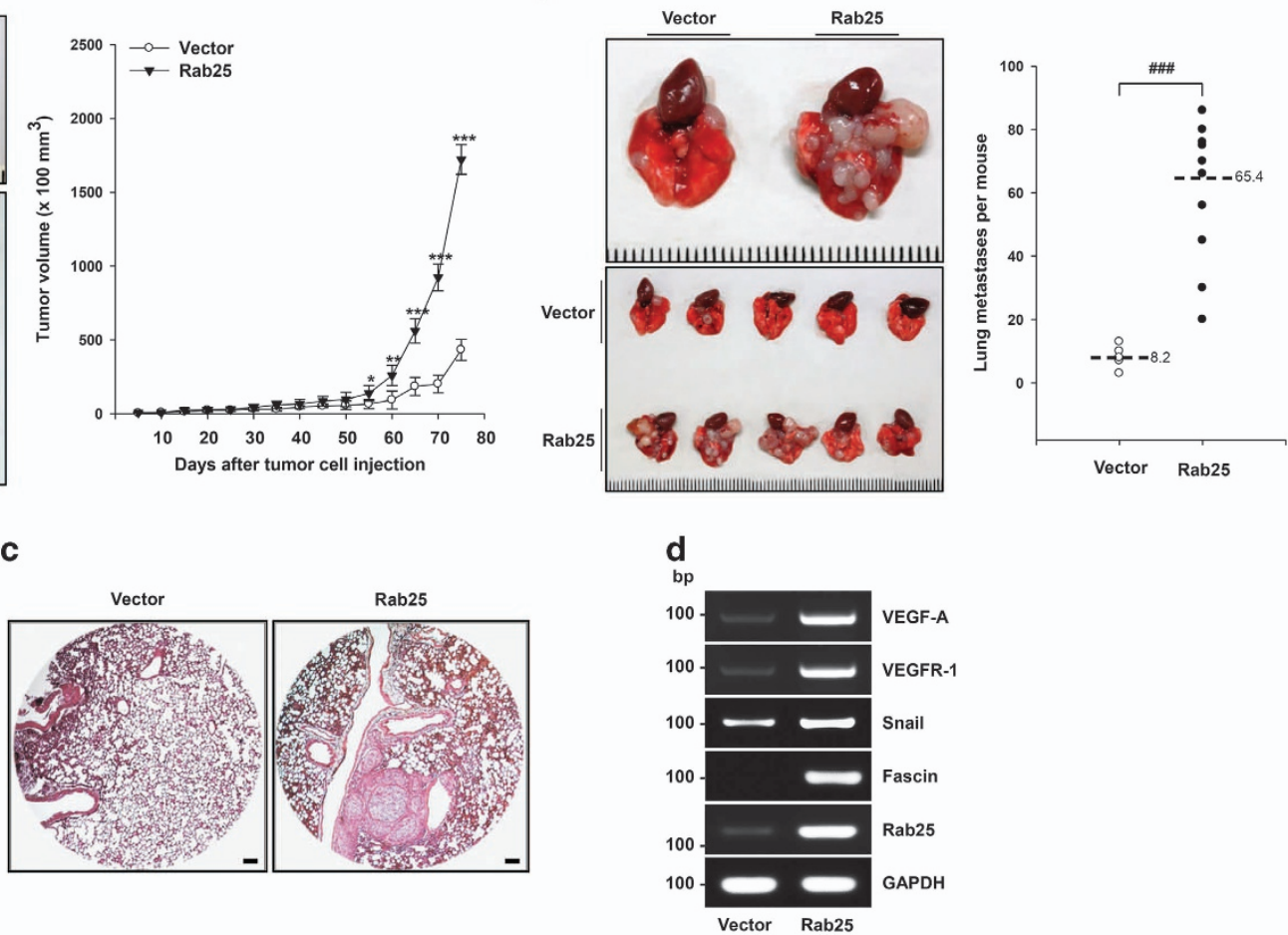

e
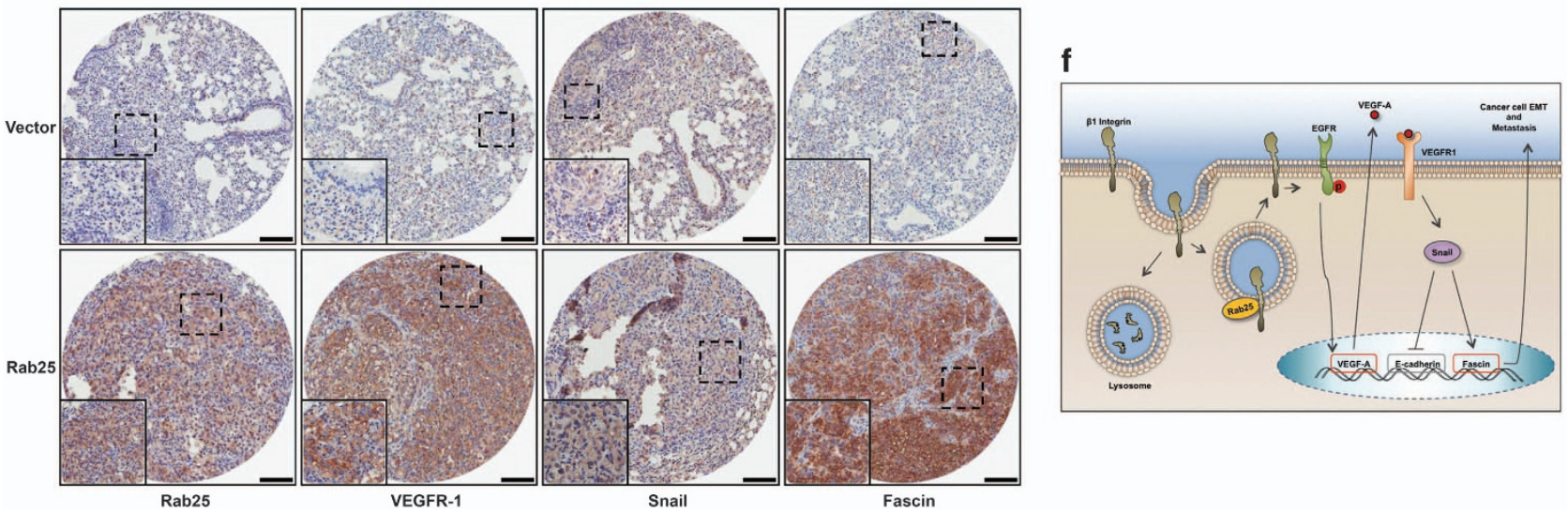

Figure 6 Rab25 increases tumorigenesis and metastasis. (a) Tumors from mice subcutaneously injected with stably transfected SKOV-3 cells with indicated vectors. Tumor dimensions were measured with calipers every 3 days (vector group number; $n=5$, Rab25 group number; $n=15$, mean \pm s.d. ${ }^{*} P<0.05,{ }^{* *} P<0.01,{ }^{* *} P<0.001$ versus vector). (b) Lungs from mice intravenously injected with stably transfected SKOV-3 cells with indicated vectors (vector group number; $n=5$, Rab25 group number; $n=10$ ). (c) Hematoxylin and eosin stain of lungs tissues. Original magnification, $\times 40$. (d) Rab25, VEGFR-1, VEGF-A, Snail and fascin mRNA levels in tumors derived from lung tissue from mice. (e) Immunohistochemical staining for Rab25, VEGFR-1, Snail and fascin in the lung tissue of mice. Scale bar, $100 \mu \mathrm{m}$. Representative results are presented from the tissues of four lungs with similar results. (f) Working model of the Rab25-induced cancer cell aggressiveness. Rab25 activates a $\beta 1$ integrin/EGFR/VEGFR-1/NEGF-A signaling axis and subsequently induces Snail and fascin expression, leading to cancer cell EMT and metastasis.

\section{DISCUSSION}

Cancer cell invasion and metastasis is the ultimate cause of death for most cancer patients. Rab25 has been shown to augment or suppress cancer cell progression depending on the cellular context. In the present study, we demonstrate the underlying mechanism by which Rab25 modulates cancer cell progression. Ectopic expression of Rab25-induced cancer cell EMT and invasion in luminal breast, ovarian and gastric cancer cells by modulating Snail and E-cadherin expression. In addition, we observed that Rab25 upregulates $\beta 1$ integrin level and subsequent EGFR activation, leading to expression of VEGF-A and stabilization of Snail protein. Interestingly, we demonstrated that Rab25- and VEGF-A-induced Snail expression not only downregulates E-cadherin expression but also increases fascin expression, leading to a startling morphological change to a mesenchymal phenotype and a marked increase in cancer cell invasion and metastasis. Therefore, these findings strongly suggest a critical role for Rab25 in cancer cell invasion 
and metastasis through a $\beta 1$ integrin/EGFR/VEGF-A/VEGFR$-1 /$ Snail signaling axis and fascin expression.

Initially, the small GTPase protein Rab25 was reported to be overexpressed in approximately half of ovarian and breast cancers and to augment tumor aggressiveness of epithelial cancers. ${ }^{3,7-9,35-37}$ However, subsequent studies suggest a tumor-suppressive role of Rab25 in several cancer lineages. ${ }^{4-6,38}$ Consistent with these findings, our current study demonstrates a context-dependent role of Rab25 in cancer cell EMT and invasion.

Accumulating data show that Rab25 induces $\beta 1$ integrin. Rab25-deficient mice decreased $\beta 1$ integrin staining in the lateral membrane of villus cells. ${ }^{5}$ In addition, Rab25 colocalized with $\alpha 5 \beta 1$ integrin, which is implicated in Caco2BBE cell invasion. ${ }^{32}$ However, previous studies suggest a tumor-suppressive role of $\beta 1$ integrin. Loss of $\beta 1$ integrin increases the invasive potential of $\mathrm{Caco} 2$ cells. ${ }^{39}$ In addition, the overexpression of $\alpha 5 \beta 1$ integrin in HT29 colon carcinoma cells dramatically reduced tumorigenicity. ${ }^{40}$ In contrast, our present studies show that Rab25 induces cancer cell invasiveness through $\beta 1$ integrin expression. In addition, we demonstrated that $\beta 1$ integrin mediates Rab25-induced EGFR activation. Consistent with these findings, we observed that RCP, known as Rab11 family-interacting protein 1 (Rab11FIP1), stabilizes $\beta 1$ integrin protein to activate EGFR, leading to Slug expression and cancer cell metastasis. ${ }^{41}$ These results suggest that Rab25 regulates cancer cell invasion in a context-dependent manner through $\beta 1$ integrin expression.

Previously, Cheng et al. ${ }^{4}$ claimed the important role of VEGFA and VEGFR-1 in Rab25-induced suppression of angiogenesis and invasion of triple-negative breast cancer. In the current study, we offer detailed mechanistic evidence that Rab25 modulates VEGF-A and VEGFR-1 expression to govern cancer aggressiveness. We observed that Rab25 upregulates VEGF-A and VEGFR-1 expression in MCF-7, SKOV-3 and MKN-1 cells. Further, we demonstrated that VEGF-A is sufficient to induce Snail expression and cancer aggressiveness. Consistent with this notion, VEGF-A stimulates Snail expression in breast cancer cells, ${ }^{42}$ suggesting that the level of VEGF-A and VEGFR-1 expression governs Rab25-induced cancer cell invasion.

Fascin has been associated with cancer progression. Fascin is overexpressed in malignant tumors compared with normal epithelial cells. ${ }^{43,44}$ Recently, Li et al. ${ }^{21}$ reported that Slug induces fascin expression to promote formation of filopodia and invasive activities of pancreatic adenocarcinoma cells. Our present study shows that Snail but not Slug mediates Rab25and subsequent VEGF-A-induced fascin expression to induce cancer cell EMT and invasiveness. Given that Rab25 affects the organization of actin at the cell surface ${ }^{37}$ and that fascin stabilizes actin in invadopodia to potentiate protrusive invasion, it is highly likely that Rab25 aggravates cancer cell invasiveness through a VEGF-A/VEGFR-1/Snail/fascin signaling cascade. Based on our current data, we present a working model (Figure 6f) in which a $\beta 1$ integrin/EGFR/VEGF-A/ VEGFR-1 signaling axis is required for Rab25-induced Snail and fascin expression.
Collectively, the present study shows that a $\beta 1$ integrin/ EGFR signaling axis governs Rab25-induced modulation of cancer invasion and that Rab25 induces Snail expression through the VEGF-A/VEGFR-1 signaling cascade to upregulate fascin expression, leading to cancer cell EMT and metastasis. Therefore, $\beta 1$ integrin, EGFR, VEGF-A, VEGFR-1, Snail and fascin should be evaluated as potential therapeutic targets to reduce invasion and metastasis of Rab25-expressing cancer cells.

\section{CONFLICT OF INTEREST}

The authors declare no conflict of interest.

\section{ACKNOWLEDGEMENTS}

We thank Professor Jong In Yook (Yonsei University, Seoul, Korea) for the plasmid containing Snail, Dr. Machesky Laura M. (Beatson Institute for Cancer Research, University of Glasgow, Glasgow, UK) for the luciferase vector of fascin. This study was supported by the Konyang University Research Fund in 2016 (HYL) and a Basic Science Research Program through the National Research Foundation of Korea (NRF) grant funded by the Korea government (NRF-2016Fostering Core Leaders of the Future Basic Science Program/Global PhD Fellowship Program (BYJ)).

\section{PUBLISHER'S NOTE}

Springer Nature remains neutral with regard to jurisdictional claims in published maps and institutional affiliations.

1 Goldenring JR, Shen KR, Vaughan HD, Modlin IM. Identification of a small GTP-binding protein, Rab25, expressed in the gastrointestinal mucosa, kidney, and lung. J Biol Chem 1993; 268: 18419-18422.

2 Calhoun BC, Goldenring JR. Rab proteins in gastric parietal cells: evidence for the membrane recycling hypothesis. Yale J Biol Med 1996; 69: 1-8.

3 Cheng KW, Lahad JP, Kuo WL, Lapuk A, Yamada K, Auersperg N et al. The RAB25 small GTPase determines aggressiveness of ovarian and breast cancers. Nat Med 2004; 10: 1251-1256.

4 Cheng JM, Volk L, Janaki DK, Vyakaranam S, Ran S, Rao KA. Tumor suppressor function of Rab25 in triple-negative breast cancer. Int J Cancer 2010; 126: 2799-2812.

5 Nam KT, Lee HJ, Smith JJ, Lapierre LA, Kamath VP, Chen X et al. Loss of Rab25 promotes the development of intestinal neoplasia in mice and is associated with human colorectal adenocarcinomas. J Clin Invest 2010; 120: 840-849.

6 Tong M, Chan KW, Bao JY, Wong KY, Chen JN, Kwan PS et al. Rab25 is a tumor suppressor gene with antiangiogenic and anti-invasive activities in esophageal squamous cell carcinoma. Cancer Res 2012; 72: 6024-6035.

7 Cao C, Lu C, Xu J, Zhang J, Li M. Expression of Rab25 correlates with the invasion and metastasis of gastric cancer. Chin J Cancer Res 2013; 25: 192-199.

8 Zhang J, Wei J, Lu J, Tong Z, Liao B, Yu B et al. Overexpression of Rab25 contributes to metastasis of bladder cancer through induction of epithelialmesenchymal transition and activation of Akt/GSK-3beta/Snail signaling. Carcinogenesis 2013; 34: 2401-2408.

9 Yin $Y X$, Shen F, Pei H, Ding Y, Zhao H, Zhao M et al. Increased expression of Rab25 in breast cancer correlates with lymphatic metastasis. Tumour Biol 2012; 33: 1581-1587.

10 Tomaskovic-Crook E, Thompson EW, Thiery JP. Epithelial to mesenchymal transition and breast cancer. Breast Cancer Res 2009; 11: 213.

$11 \mathrm{He} \mathrm{H}$, Chen W, Wang X, Wang C, Liu F, Shen Z et al. Snail is an independent prognostic predictor for progression and patient survival of gastric cancer. Cancer Sci 2012; 103: 1296-1303.

12 Elloul S, Elstrand MB, Nesland JM, Trope CG, Kvalheim G, Goldberg I et al. Snail, Slug, and Smad-interacting protein 1 as novel parameters of disease 
aggressiveness in metastatic ovarian and breast carcinoma. Cancer 2005; 103: 1631-1643.

13 Blechschmidt K, Sassen S, Schmalfeldt B, Schuster T, Hofler H, Becker KF. The E-cadherin repressor Snail is associated with lower overall survival of ovarian cancer patients. Br J Cancer 2008; 98: 489-495.

14 Blanco MJ, Moreno-Bueno G, Sarrio D, Locascio A, Cano A, Palacios J et al. Correlation of Snail expression with histological grade and lymph node status in breast carcinomas. Oncogene 2002; 21: 3241-3246.

15 Shin NR, Jeong $\mathrm{EH}$, Choi $\mathrm{Cl}$, Moon $\mathrm{HJ}$, Kwon $\mathrm{CH}$, Chu IS et al. Overexpression of Snail is associated with lymph node metastasis and poor prognosis in patients with gastric cancer. BMC Cancer 2012; 12: 521.

16 Adams JC. Formation of stable microspikes containing actin and the 55 $\mathrm{kDa}$ actin bundling protein, fascin, is a consequence of cell adhesion to thrombospondin-1: implications for the anti-adhesive activities of thrombospondin-1. J Cell Sci 1995; 108(Pt 5): 1977-1990.

17 Kureishy N, Sapountzi V, Prag S, Anilkumar N, Adams JC. Fascins, and their roles in cell structure and function. Bioessays 2002; 24: 350-361.

18 Yoder BJ, Tso E, Skacel M, Pettay J, Tarr S, Budd T et al. The expression of fascin, an actin-bundling motility protein, correlates with hormone receptornegative breast cancer and a more aggressive clinical course. Clin Cancer Res 2005; 11: 186-192.

19 Hashimoto Y, Shimada Y, Kawamura J, Yamasaki S, Imamura M. The prognostic relevance of fascin expression in human gastric carcinoma. Oncology 2004; 67: 262-270.

20 Hayashi Y, Osanai M, Lee GH. Fascin-1 expression correlates with repression of $\mathrm{E}$-cadherin expression in hepatocellular carcinoma cells and augments their invasiveness in combination with matrix metalloproteinases. Cancer Sci 2011; 102: 1228-1235.

$21 \mathrm{Li}$ A, Morton JP, Ma Y, Karim SA, Zhou Y, Faller WJ et al. Fascin is regulated by slug, promotes progression of pancreatic cancer in mice, and is associated with patient outcomes. Gastroenterology 2014; 146 1386-1396.e1-17.

22 Zhang J, Cheng Q, Zhou Y, Wang Y, Chen X. Slug is a key mediator of hypoxia induced cadherin switch in HNSCC: correlations with poor prognosis. Oral Oncol 2013; 49: 1043-1050.

23 Mitra S, Federico L, Zhao W, Dennison J, Sarkar TR, Zhang F et al. Rab25 acts as an oncogene in luminal B breast cancer and is causally associated with Snail driven EMT. Oncotarget 2016; 7: 40252-40265.

24 Yook JI, Li XY, Ota I, Fearon ER, Weiss SJ. Wnt-dependent regulation of the E-cadherin repressor snail. J Biol Chem 2005; 280: 11740-11748.

25 Park SY, Jeong KJ, Panupinthu N, Yu S, Lee J, Han JW et al. Lysophosphatidic acid augments human hepatocellular carcinoma cell invasion through LPA1 receptor and MMP-9 expression. Oncogene 2011; 30: 1351-1359.

26 Lee J, Park SY, Lee EK, Park CG, Chung HC, Rha SY et al. Activation of hypoxia-inducible factor-1alpha is necessary for lysophosphatidic acidinduced vascular endothelial growth factor expression. Clin Cancer Res 2006; 12: 6351-6358.

27 Kim SH, Cho KH, Kim YN, Jeong BY, Park CG, Hur GM et al. Resveratrol attenuates norepinephrine-induced ovarian cancer invasiveness through downregulating hTERT expression. Arch Pharm Res 2016; 39: 240-248.

28 Choi MJ, Cho KH, Lee S, Bae YJ, Jeong KJ, Rha SY et al. hTERT mediates norepinephrine-induced Slug expression and ovarian cancer aggressiveness. Oncogene 2015; 34: 3402-3412.

29 Kim YN, Choe SR, Cho KH, Cho DY, Kang J, Park CG et al. Resveratrol suppresses breast cancer cell invasion by inactivating a RhoA/YAP signaling axis. Exp Mol Med 2017; 49: e296.

30 Jeong KJ, Park SY, Cho KH, Sohn JS, Lee J, Kim YK et al. The Rho/ROCK pathway for lysophosphatidic acid-induced proteolytic enzyme expression and ovarian cancer cell invasion. Oncogene 2012; 31: 4279-4289.
31 Park SY, Kang JH, Jeong KJ, Lee J, Han JW, Choi WS et al. Norepinephrine induces VEGF expression and angiogenesis by a hypoxia-inducible factorlalpha protein-dependent mechanism. Int J Cancer 2011; 128: 2306-2316.

32 Krishnan M, Lapierre LA, Knowles BC, Goldenring JR. Rab25 regulates integrin expression in polarized colonic epithelial cells. Mol Biol Cell 2013; 24: 818-831.

33 Tringali C, Lupo B, Silvestri I, Papini N, Anastasia L, Tettamanti G et al. The plasma membrane sialidase NEU3 regulates the malignancy of renal carcinoma cells by controlling beta1 integrin internalization and recycling. $J$ Biol Chem 2012; 287: 42835-42845.

34 Kulasingam V, Diamandis EP. Fascin-1 is a novel biomarker of aggressiveness in some carcinomas. BMC Med 2013; 11: 53.

35 Mills GB, Jurisica I, Yarden Y, Norman JC. Genomic amplicons target vesicle recycling in breast cancer. J Clin Invest 2009; 119: 2123-2127.

36 Dozynkiewicz MA, Jamieson NB, Macpherson I, Grindlay J, van den Berghe PV, von Thun A et al. Rab25 and CLIC3 collaborate to promote integrin recycling from late endosomes/lysosomes and drive cancer progression. Dev Cell 2012; 22: 131-145.

37 Amornphimoltham P, Rechache K, Thompson J, Masedunskas A, Leelahavanichkul K, Patel V et al. Rab25 regulates invasion and metastasis in head and neck cancer. Clin Cancer Res 2013; 19: 1375-1388.

38 Cheng JM, Ding M, Aribi A, Shah P, Rao K. Loss of RAB25 expression in breast cancer. Int J Cancer 2006; 118: 2957-2964.

39 Kuwada SK, Li X. Integrin alpha5/beta1 mediates fibronectin-dependent epithelial cell proliferation through epidermal growth factor receptor activation. Mol Biol Cell 2000; 11: 2485-2496.

40 Varner JA, Emerson DA, Juliano RL. Integrin alpha 5 beta 1 expression negatively regulates cell growth: reversal by attachment to fibronectin. $\mathrm{Mol}$ Biol Cell 1995; 6: 725-740.

41 Hwang $\mathrm{MH}$, Cho KH, Jeong KJ, Park YY, Kim JM, Yu SL et al. RCP induces Slug expression and cancer cell invasion by stabilizing betal integrin. Oncogene 2017; 36: 1102-1111.

42 Wanami LS, Chen HY, Peiro S, Garcia de Herreros A, Bachelder RE. Vascular endothelial growth factor-A stimulates Snail expression in breast tumor cells: implications for tumor progression. Exp Cell Res 2008; 314: 2448-2453.

43 Hashimoto Y, Kim DJ, Adams JC. The roles of fascins in health and disease. J Pathol 2011; 224: 289-300.

44 Li A, Dawson JC, Forero-Vargas M, Spence HJ, Yu X, Konig I et al. The actin-bundling protein fascin stabilizes actin in invadopodia and potentiates protrusive invasion. Curr Biol 2010; 20: 339-345.

\begin{abstract}
This work is licensed under a Creative Commons Attribution-NonCommercial-NoDerivs 4.0 International License. The images or other third party material in this article are included in the article's Creative Commons license, unless indicated otherwise in the credit line; if the material is not included under the Creative Commons license, users will need to obtain permission from the license holder to reproduce the material. To view a copy of this license, visit http://creativecommons.org/licenses/by-nc-nd/4.0/
\end{abstract}

(C) The Author(s) 2018

Supplementary Information accompanies the paper on Experimental \& Molecular Medicine website (http://www.nature.com/emm) 